\title{
Evolution of Creation Buddhist Lent Candle of Work Awarded in Ubon Ratchathani's Lent Candle Contests 2003-2007
}

\author{
Sakchai Uttitho \\ Department of Visual Art, Faculty of Fine and Applied Art, Mahasarakham University, Maha Sarakham, Thailand
}

Received 2012-08-29, Revised 2012-08-22; Accepted 2012-08-29

\begin{abstract}
The tradition of Lent candle procession at the Buddhist Lent festival is the grand festival at the national level in Ubon Ratchathani province. From the merit-making tradition concerning Buddhism binding to the way of life of Isan people for the long time, this festival has developed to be a tourist festival at the national level. Later, there have been contests of candle making in continuity. Throughout the past time the contests have promoted creation of candle with different styles contests and stories which are valuable for studying and dissemination in the future. The purposes of this research were to examine the background of the Buddhist Lent candle trees, elements of contests and evaluation of candle trees awarded on Lent candle contests in Ubon Ratchathani province from 2003-2007. The research area covered Ubon Ratchathani provinces where Buddhist Lent candle were created for contests which were the most famous in Thailand. The research procedure used the qualitative research methodology. Data were collected from related literature and field studies using survey, observations, interviews and focus group discussion from a group of totally 35 informants. The findings were presented by means of a descriptive analysis. The results reviewed that candle trees had been made for neatness contests since 1927. In 1977 the tradition of Lent candle procession week was held to be a grand annual festival of the province. Candle trees were contested in 3 types. Later two elements of contest consisted of large-sized candle tree and small-sized candle tree. Concepts of candle tree creation were from the criteria determined by Ubon Ratchathani province. The criteria were different from year to year. The stories to created as candle trees were about Buddhism local culture and identities of Ubon Ratchathani. The same criteria were use for decision making in every type by considering from candle tree base and all elements, The evaluation of candle trees awarded in contests could be divided into 3 aspects: contests the stories appearing the most involved the Lord Buddha stories. The shape of the Buddha images used was in sitting style. There were 4 forms using structural line to determine the front part, middle part and the end part at different heights. The Buddhist Lent candle trees creation was originate from belief in Buddhism presented by Buddhists to Buddhism monks who stayed at their monasteries. Ubon Ratchathani province has adhered to this tradition from ancient time up to present. The tradition has been promoted by the state and private sectors. It is a grand traditional festival. There are candle trees contest every year. Most of the contents appearing at the candle trees in contests are stories in Buddhism. However, some year there are contents concerning His Majesty the King in different auspicious occasion. There are limited families of craftsmanship so the forms of candle trees are similar. They are popularistic and realistic. The same shapes are used but elements are adjusted.
\end{abstract}

Keywords: Forms of Buddhist Lent Candles, Creation of Buddhist Lent Candle Trees, Content

\section{INTRODUCTION}

Custom and tradition generated from learning. They have been accumulated for a long time until they assimilated into the way of life and become local identity and they are adhered to up to the present. Most of Thai traditions are related to Buddhism. Which community people belief in and have faith in Buddhism Lent candle are big candles used in the monasteries during the rainy season. Traditional Lent candle procession in the Buddhist tradition of Ubon Ratchathani people in which Buddhist property, culture and tradition have appear for 
a long time. It is the greated merit-festival in the locality. This festival is held between Asalha Puja and Vassa every year. (Kaeolan et al., 2011) Lent candle trees creation from ancient belief has change from the past. Technological advancements can cause craftmen to created large candle trees with beautiful pattern easier and faster. Social and economic changed cause state and private sector to participate more in activities. There are candle trees contest and awards in return to winner. The purposes of candle making have changed from traditional beliefs. For there reasons, the author, conducted a study of Buddhist Lent candle awarded from 2003-2007 of Ubon Ratchathani province in order to conserved, adhere and to cultivate awareness of love and pride of local tradition.

\section{MATERIALS AND METHODS}

The qualitative research methodology was used. Data were collected from related literature and field studies. The research area purposively selected was Ubon Ratchathani where there have been concerning Buddhist Lent candle for created in Thailand. The research was conducted using a primary survey form, a non-participant observations, a non-structured interview form and focus group discussion with a group of totally 35 informants. The collected data were checked for correctness and completeness using the methodological triangulation technique. The research findings were checked by qualified person in the field of fine art. The study results were presented by means of a descriptive analysis.

\section{RESULTS}

\subsection{The Background of the Buddhist Lent Candle Tree Contests, in Ubon Ratchathani}

Ubon Ratchathani people had created Lent candle trees for contests from 1927. In the past, in making candle to offer to Buddhist monks, each candle was made by making it about around the-head-long for monk to light it to worshiping during the Buddhist Lent. In the early period, candle were made of real bee wax. However, the candle form began to change when the villagers donated candles by tying them together using bamboo or pieces of betel palm tree, putting candle together in layers from the base to be top of axis. Then silver paper golden paper transparent paper with different colors were cut in the zig zag form and were put on the candle space, After that the candle were offered to Buddhist monk. Each candle could be separately used. Later, candles were light together like candle bushes. Candle trees were neatly decorated using various methods of decoration. Later, candle patterns of flowers were made from printed cloths. The candle base were decorated with carved picture of animals and carved the wood causing more beauty. Next, made candles were made by casting. Candle trees were large with variety of patterns and compositions. After that, people realized more the importance of candle process tradition. In 1977 Ubon Ratchathani provincial government held the week of Buddhist Lent candle procession festival to be a grand tradition. In the area of Thung Sri Muang Ground. At the early type of candle trees were contested they were a type of lighting candles together stuck with paper of different colors and a type of printing patterns around the candle tree. Later, a type of carving was added so there were 3 types. In 1977 H.M. the King Bhumibol Adulyadej kindly gave the loyal candle as the major candle to join the annual candle process for the first time. Candle process festival was promoted more from the provincial government until The Tourism Authority of Thailand supported and upgraded it to become the national festival, causing the Buddhist Lent candle procession festival in Ubon Ratchathani to be popular among Thai and foreign tourists. In 2006 International Candle sculpture to promote conservation of Isan tradition culture adhere and develop Isan craftsmanship carving candle sculpture by famous artists from 9 countries.

\subsection{Elements of Buddhist Lent Candle Contest}

There were the following 3 elements:

- The criteria for contest assigned for each type were (Kaeolan et al., 2011) the large-sized candle tree with the following elements; Each candle tree having wick and its base of $2 \mathrm{~m}$ high, but not exceeding $3 \mathrm{~m}$ from the base. The base must be 30 centimeters in diameter. Suksri et al. (2010) each small-sized with the following elements; each candle tree having wick and its base of $1 \mathrm{~m}$ high, but not exceeding $2.5 \mathrm{~m}$ from the base. The base must be 20 centimeters and at the narrowest past must not lens than 70 centimeters and the underlying element of the candle tree must be decorated to relate to Buddhism, local culture and identity of Ubon Ratchathani only

- Concept of creating the candle trees which were award in the contests came from the determine criteria. The story to create as element of candle trees must relate to Buddhism to culture and identity of Ubon Ratchathani

- Criteria for decision of the committee for the decision criteria, the committee use the same criteria. Rating was considered from the candle trees and base for 60 marks and the hole element for 40 marks. 

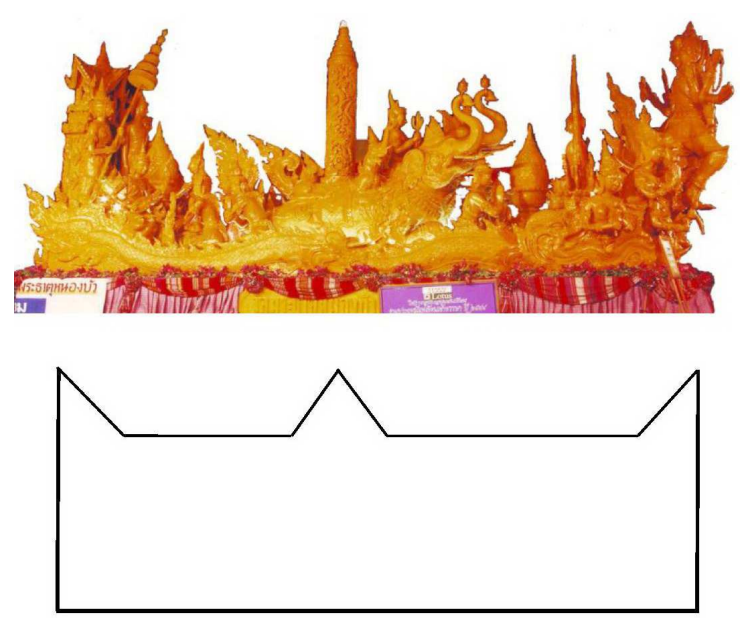

Fig. 1. The form with the same height of front, central [the candle tree] and back part

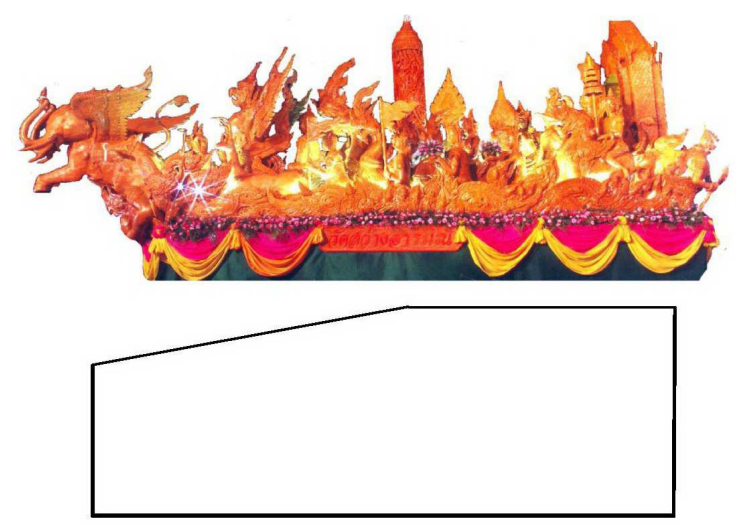

Fig. 2. The form with low front part but the same height of the central [the candle tree] and back parts

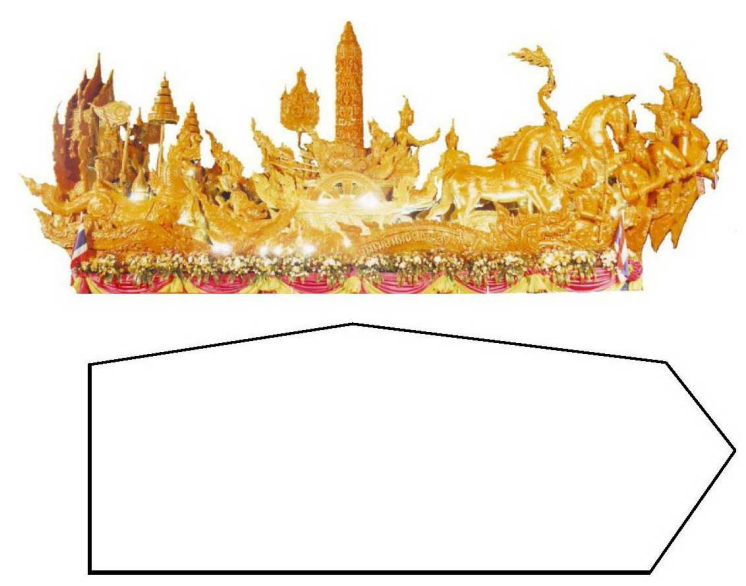

Fig. 3. The form with the same lowest of the front and the back part but with height central part

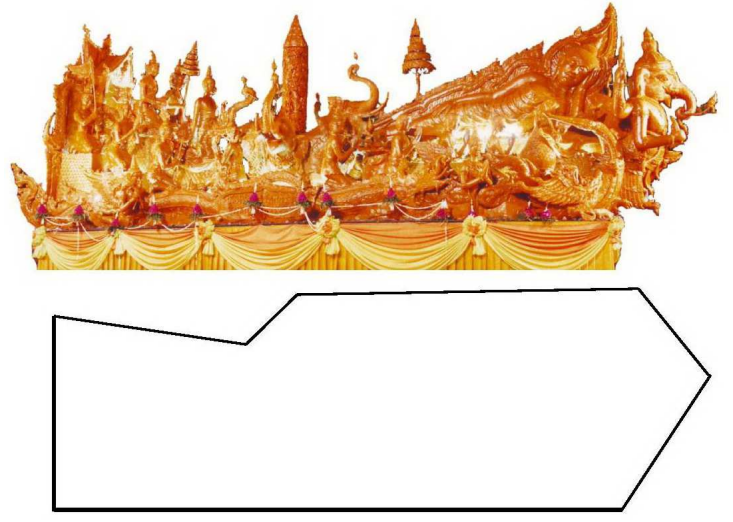

Fig. 4. The form with the same height of the front and the central part but with the low back part

\subsection{The Evolution of the Candle Trees with were Awarded in the Contests}

Would be divided in 3 aspects:

- $\quad$ For content, the stories appeared the most concerning Buddhism which included that: Toschat Chadok Tosukata Jatakas. The Jatakas use the most were Vessantara Jatakas and Phra maha Janka Jatakas', the lord Buddha stories use the most were the part Three Preached His-5 Followers. The part of Enliken Enlightened and the part Tree he preached in Mercy to His Mother

- For the shape of the His Buddha images use for candle tree decoration was sitting style as a meditation style or Enlightenment style. The imaginary animals use the most was Naga, next were Garuda and Kinari. Sometime Gods in Brahinn Hindo were also used to decorate candle trees

- For the form using structural line, the line drawn using imaginations were determined using eye right were in algebraic shape. There were

Kaeolan et al. (2011) the form with the same height of the front, the central [the candle tree] and back part. That was shown in Fig. 1.

Suksri et al. (2010) the form with low front part but the same height of the central [the candle tree] and back parts. That was shown in Fig. 2.

Duangsin et al. (2011) the form with the same lowest of the front and the back part but with height central part [the candle tree]. That was shown in Fig. 3.

Booncham et al. (2011) the form with the same height of the front and the central part [the candle tree] but with the low back part as the Fig. 4. 


\section{DISCUSSION}

Lent candle tree creation in the past generated from Buddhist beliefs which Buddhism offered to Buddhist monks who took Buddhist Lent at the monasteries Ubon Ratchathani province has adhered to this tradition from the ancient time. At present it is supported by the state and private sector. It has been developed to the grand festival of the nation. Suksri et al. (2010) there are contests and awards to encourage economic result and tourisms rather than offering them to the monastery like in the past. It has led to creation of fantastic candle trees. Most of the content is accounts in the Lord Buddha stories. In some year there were content about H.M. the King in different auspicious occasion.

Duangsin et al. (2011) However, there were limited family of craftmen the form of candle trees consisted of contents neatness and beauty and complete accounts as determined each year. For decision in the past, the committees consisted of persons in the position of governing. The decision criteria were inconformity with committee's feeling. At present, more committee members selected from person with knowledge of Visual Art for decision-making criteria are rating according to the determine criteria which are officially announce. Therefore, decisions are more reliable (Booncham et al., 2011).

\section{CONCLUSION}

In the past, wax was made into long line and was tied together. The wax was decorated with color papers or natural material such as flowers and banana leaves. Until 1937 there was technical development candles were made larger to have more candle area. Later, models made on the stone and candle was made into patterns. They put on the candle trees there were continuous developments. In 1959 candle carving was invented for the first time but an emphasize was on the candle trees only. The importance on the base of the candle trees was not given. In 1977 the week of the Lent Candle Procession was held as a grand festival there were contests of different type of candle trees. Large crowds of people came to join the festival. Tourism Authority of Thailand officially supported the festival to be the provincial identity. Larger candle trees were made continually. More manpower budgets were needed. In 2006 there was the celebration on the 60th Anniversary
Celebration of H.M. the King's Accession to the Throne. International Lent Candle Tree was carved. Foreign artists were invited to created visual art works from candle. The forms, contents and techniques of artists from each country which were used for creation may cause changer to the festival organization and the form of Buddhists Lent candles in Ubon Ratchathani province.

\section{ACKNOWLEDGEMENT}

This dissertation received a sponsorship for the fiscal year 2007 from Mahasarakham University. The researchers express their sincere appreciation and thanks for all of those who supported in one way or another.

\section{REFERENCES}

Booncham, A., S. Chantachon and S. Lao-Akka, 2011. Contemporary sculptures: Decoding the body of aesthetic knowledge suitable for public parks. Am. J. Applied Sci., 8: 1302-1306. DOI: 10.3844/ajassp.2011.1302.1306

Duangsin, T., S. Chantachon and K. Paengsoi, 2011. Buddhist philosophy: A study of buddha images for perpetuating buddhism in Isan society. J. Soc. Sci., 7: 149-151. DOI: 10.3844/jssp.2011.149.151

Kaeolan, P.K.W.P., B. Yodmalee and S. Phothisane, 2011. Buddhist monk preachers: A study of preaching arts for increasing faith in Buddhism of Isan people. J. Soc. Sci., 7: 271-273. DOI: 10. 3844/jssp.2011.271.273

Suksri, A., S. Phothisane, S. Laoakka, N. Thongwol and B. Saenyabud, 2010. The Buddha images and conservation and adherence to cultural values in Northeast. J. Soc. Sci., 6: 320-323. DOI: $10.3844 /$ jssp. 2010.320 